\title{
Growth hormone prevents acute liver injury induced by cardiopulmonary bypass in a rat model
}

Yong An, MD, and Ying-Bin Xiao, MD

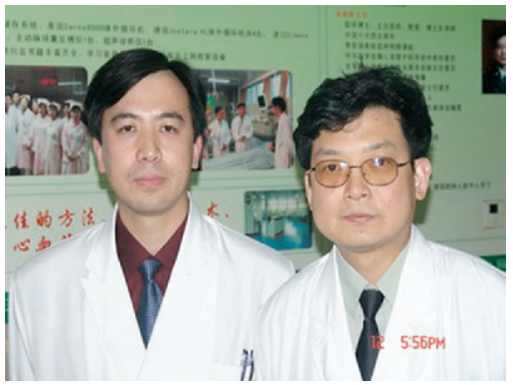

Drs An and Xiao (left to right)
From the Department of Cardiovascular Surgery, Xin-Qiao Hospital, Third Military Medical University, Chongqing, China.

Received for publication Nov 13, 2006; revisions received Feb 7, 2007; accepted for publication Feb 14, 2007.

Address for reprints: Ying-Bin Xiao, MD, Department of Cardiovascular Surgery, Xin-Qiao Hospital, Third Military Medical University, ShaPingBa District, Chongqing 400037, China (E-mail: anyongsmevs@ 163.com).

J Thorac Cardiovasc Surg 2007;134:342-50 $0022-5223 / \$ 32.00$

Copyright () 2007 by The American Association for Thoracic Surgery

doi:10.1016/j.jtcvs.2007.02.036
Objective: Cardiopulmonary bypass-induced acute liver injury is a life-threatening complication thought to be associated with the inflammatory response and the acute-phase response. Recombinant human growth hormone can modulate the acute-phase response and inflammatory response. We tested the protective effect of growth hormone on cardiopulmonary bypass-induced liver injury in the rat.

Methods: Adult male Sprague-Dawley rats (group G received $2.5 \mathrm{mg} / \mathrm{kg}$ recombinant human growth hormone intramuscularly at 8 Am every 24 hours for 3 days and just before the initiation of cardiopulmonary bypass; group $\mathrm{C}$ served as a control group) underwent cardiopulmonary bypass $\left(120\right.$ minutes, $120 \mathrm{~mL} \cdot \mathrm{kg}^{-1} \cdot \mathrm{min}^{-1}$, $34^{\circ} \mathrm{C}$ ) and were killed 3 hours after the termination of cardiopulmonary bypass.

Results: Administration of recombinant human growth hormone markedly increased serum insulin-like growth factor and insulin-like growth factor-binding protein 3 levels compared with those seen in group C. Group G showed significantly lower serum concentrations of alanine aminotransferase and total bilirubin after cardiopulmonary bypass termination. Those receiving recombinant human growth hormone demonstrated a significant increase in serum prealbumin and transferrin levels and a marked decrease in serum amyloid A and C-reactive protein levels. Recombinant human growth hormone significantly decreased serum tumor necrosis factor $\alpha$ and interleukin $1 \beta$ levels, whereas no changes were found for serum interleukin 6 and interleukin 10 levels. Recombinant human growth hormone significantly increased total liver protein content and hepatocyte proliferation and decreased hepatocyte apoptosis versus values seen in group C.

Conclusions: These results suggest that growth hormone prevents cardiopulmonary bypass-induced acute liver injury in a rat model through decreases in acute-phase proteins, proinflammatory cytokines tumor necrosis factor $\alpha$ and interleukin $1 \beta$, and hepatocyte apoptosis, which is associated with increases in constitutive hepatic proteins, total liver protein content, and hepatocyte proliferation. This strategy of pretreatment with growth hormone might be a prospective management for preventing acute liver injury when major cardiac surgery with cardiopulmonary bypass is performed.

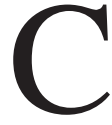

ardiopulmonary bypass (CPB) causes severe stress in the cardiac patient, which can provoke a systemic inflammatory response syndrome. ${ }^{1}$ The proinflammatory cytokines are potent inducers of the hepatic acute-phase protein (APP) synthesis. These excess inflammatory responses and prolonged acutephase responses (APRs) injure various organs and contribute to morbidity and mortality after cardiac surgery with CPB. The liver is one of the organs vulnerable to the attack of proinflammatory cytokines. It has long been recognized that early jaundice and liver lesions could appear after CPB surgery. ${ }^{2,3}$ Recent studies have explored whether pharmacologic intervention before reperfusion rather than during the preservation period could preserve function in vital organs undergoing CPB- 


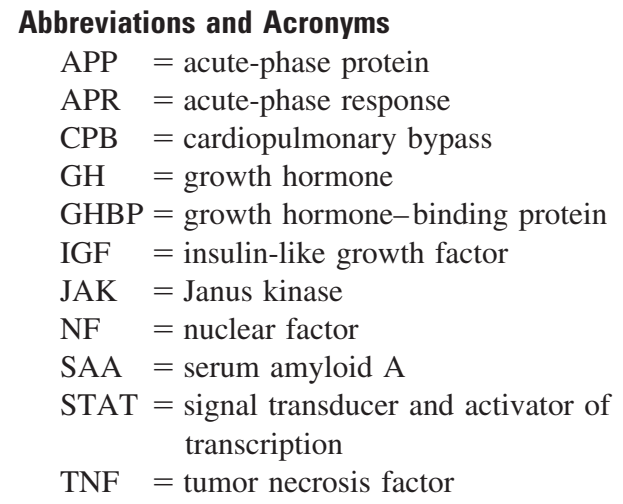

induced inflammatory response and APR..$^{4-9}$ Building tolerance to perioperative damage during the unstressed condition might result in a more advanced method to assuage CPB-induced inflammatory response and APR, and exploiting a natural defense mechanism called stress response might be a potential approach to overcome this problem.

Hepatic APR is an orchestrated cascade of events in response to tissue injury, infection, or inflammatory response. Growth hormone (GH) has been shown to enhance immune function and to diminish the hypermetabolic response after major operations, trauma, sepsis, or thermal injury. ${ }^{10-15}$ However, the interaction between the liver and recombinant human growth hormone (rhGH) after CPB has not been defined. In the current study we tested the in vivo effect of GH using a rat CPB model.

\section{Materials and Methods Animal Care}

Adult male Sprague-Dawley rats weighing $480 \pm 20 \mathrm{~g}$ (Animal Supplier Center of Third Military Medical University, Chongqing, China) were housed in wire-bottomed cages in a temperaturecontrolled room with a 12-hour light/dark cycle. Rats were acclimatized to the environment for 7 days. All animals received humane care in compliance with the European Convention on Animal Care. The study was reviewed and approved by the Animal Care and Use Committee of the Third Military Medical University and followed the National Research Council's guidelines.

\section{Group Classification}

Thirty rats were randomly divided into one of 2 groups according to the administration of $\mathrm{GH}$ before the initiation of CPB. Group $\mathrm{G}$ $(\mathrm{n}=15)$ intramuscularly received $2.5 \mathrm{mg} / \mathrm{kg}$ body weight of $\mathrm{rhGH}$ (Serono, Inc) at 8 AM every 24 hours for 3 days and just before the initiation of CPB. Group C $(\mathrm{n}=15)$ served as a control group and received only saline added in the same way.

All rats underwent 120 minutes of CPB $\left(120 \mathrm{~mL} \cdot \mathrm{kg}^{-1}\right.$. $\min ^{-1}, 34^{\circ} \mathrm{C}$, without aortic crossclamping or cardioplegic arrest) and were killed 3 hours after the termination of CPB. Ten rats from each group were used for blood analysis. The remaining 10 rats (5 from each group) were used for histologic examinations.

\section{Surgical Procedures for Rat CPB}

Rats were anesthetized by means of intraperitoneal administration of urethane $(1 \mathrm{mg} / \mathrm{kg})$ and placed in the supine position. During the operation, the rat was ventilated with a 14-gauge cannula (fraction of inspired oxygen, 1.0; frequency, 65 breaths/min; tidal volume, $10 \mathrm{~mL} / \mathrm{kg}$ body weight) by the use of a rodent ventilator (Rodent Respirator, DH-150). Ventilation was finely adjusted to maintain a $\mathrm{PaCO}_{2}$ of 35 to $40 \mathrm{~mm} \mathrm{Hg}$. During CPB, additional urethane was inflated into the oxygenator to maintain anesthesia. The left femoral artery was cannulated with a 22-gauge heparinized catheter (BD Intima-2 integrated catheter) for continuous pressure measurement and to collect arterial blood gas analysis (blood gas analyzer, GEM Premier 3000). The homolateral femoral vein was cannulated with a 20-gauge catheter for liquid replacement. An 18-gauge catheter was inserted into the right jugular vein and advanced to the right atrium. This position resulted in good drainage. Subsequently, the left carotid artery was exposed and cannulated with a 22-gauge catheter placed into the aortic arch that served as the arterial perfusion line for the extracorporeal circuit. For anticoagulation, heparin (300 IU/kg) was applied; half of the dose was administered directly through the left femoral catheter, and the other half was administered into the extracorporeal circuit.

The CPB circuit was composed of a roller pump (Polystan $\mathrm{A} / \mathrm{S}$ ), a hollow-fiber oxygenator (surface area, $0.075 \mathrm{~m}^{2}$; especially made by Xijing Medical Instruments, Inc), a poikilothermy water tank (Sarns Machine), a venous reservoir (BD, 20-mL injection syringes), and sterile tubing with an inner diameter of $4 \mathrm{~mm}$ for the venous line and $1.6 \mathrm{~mm}$ for the arterial line. The high siphon level was $30 \mathrm{~cm}$. The blood was drained from the right atrium through the right jugular by means of gravity and siphoning and further transferred by the roller pump to the hollow-fiber oxygenator and back to the rat through the left carotid artery. Priming consisted of $8 \mathrm{~mL}$ of plasma expander, $2 \mathrm{~mL}$ of $7 \%$ sodium bicarbonate, $2 \mathrm{~mL}$ of mannitol, $4 \mathrm{~mL}$ of LR solution, and $1.5 \mathrm{mg}$ of tobramycin. Furthermore, the GH group rats received $10 \mathrm{mg} / \mathrm{kg}$ rhGH intramuscularly 30 minutes before the establishment of CPB. CPB was stably performed at $120 \mathrm{~mL} \cdot \mathrm{kg}^{-1} \cdot \mathrm{min}^{-1}$ for 120 minutes, and perfusate temperature was set at $34^{\circ} \mathrm{C}$. At the initiation of $\mathrm{CPB}$, the flow rate was gradually adjusted to a level that could sustain the mean arterial pressure near $80 \mathrm{~mm} \mathrm{Hg}$; at this point, ventilation was terminated. During CPB, mean arterial pressure was regulated at 60 to $80 \mathrm{~mm} \mathrm{Hg}$. Heart rate was monitored by means of electrocardiography. The hematocrit value was about $25 \%$ to $30 \%$. With a fraction of inspired oxygen of $100 \%, 50 \mathrm{~mL} / \mathrm{min}$ gas flows were sufficient to achieve adequate oxygenation and to maintain $\mathrm{PaCO}_{2}$ within 35 to $40 \mathrm{~mm} \mathrm{Hg}$. After weaning from the circuit, heparin was neutralized with $1 \mathrm{mg}$ of protamine for each 100 units of heparin. The remaining priming solution was infused gradually after the termination of CPB. Routinely, termination of CPB was aided by continuous administration of dobutamine $\left(3 \mu \mathrm{g} \cdot \mathrm{kg}^{-1}\right.$. $\left.\min ^{-1}\right)$. Perioperative hemodynamic data are shown in Table 1.

\section{Blood Analysis}

Arterial blood was sampled at the following 3 times: (1) before the initiation of CPB, (2) at the termination of CPB, and (3) 3 hours after the termination of CPB. 
Table 1. Perioperative hemodynamic data

\begin{tabular}{|c|c|c|c|c|}
\hline Variables & Groups & Pre-CPB & Off CPB & After $3 \mathrm{~h}$ \\
\hline \multirow[t]{2}{*}{ Heart rate (beats/min) } & Group C & $360 \pm 18$ & $378 \pm 15$ & $338 \pm 16$ \\
\hline & Group $\mathrm{G}$ & $355 \pm 21$ & $385 \pm 19$ & $332 \pm 13$ \\
\hline \multirow[t]{2}{*}{ Mean arterial pressure $(\mathrm{mm} \mathrm{Hg})$} & Group C & $82.5 \pm 2.1$ & $76.5 \pm 6.3$ & $81.7 \pm 5.2$ \\
\hline & Group G & $78.6 \pm 3.3$ & $80.1 \pm 5.0$ & $86.3 \pm 7.1$ \\
\hline
\end{tabular}

Data are expressed as means \pm standard deviation. $C P B$, Cardiopulmonary bypass; pre- $C P B$, before the initiation of $C P B$; off $C P B$, at the termination of $\mathrm{CPB}$; after 3 h, 3 hours after $\mathrm{CPB}$ termination; group $C$, control group; group $G$, growth hormone administration group.

\section{Measurements}

Serum GH, growth hormone-binding protein, insulin-like growth factor, and insulin-like growth factor-binding protein 3. Serum human and endogenous rat GH concentrations were determined by using a human GH radioimmunoassay (Nichols Institute Diagnostics) or a rat $\mathrm{GH}$ radioimmunoassay (Biosource Int) to determine whether the rhGH was biologically active and caused a response. Serum growth hormone-binding protein (GHBP), insulin-like growth factor (IGF) I, and insulin-like growth factor-binding protein (IGFBP) 3 levels were determined by means of radioimmunoassay (Biosource Int).

Liver function. Blood samples were analyzed for serum concentration of albumin, alanine aminotransferase, and total bilirubin by using an automated biochemical analyzer (Beckman Array 3000).

Serum constitutive hepatic proteins and APPs. We measured serum constitutive hepatic proteins, such as prealbumin and transferrin; type I serum APPs, such as C-reactive protein (CRP) and $\alpha_{1}$-acid glycoprotein; and type II APPs, such as heptoglobin and $\alpha_{1}$-antitrypsin, by using a Behring nephelometer (Behring). We determined type I serum amyloid A (SAA) APP levels by means of enzyme-linked immunosorbent assay (Genzyme).

Serum cytokines. We determined serum tumor necrosis factor (TNF) $\alpha$, interleukin (IL) $1 \beta$, IL-6, and IL-10 levels by using a rat-specific enzyme-linked immunosorbent assay (Genzyme).

Liver changes. All rats were killed 3 hours after the termination of CPB. The entire liver was harvested, weighed, and sectioned. One section $(500 \mathrm{mg}$ ) was fixed in $4 \%$ formalin for histologic examination, 1 section $(500 \mathrm{mg}$ ) was used for wet/dry weight ratios, and 1 section $(5 \mathrm{~g})$ was snap-frozen in liquid nitrogen for storage. Hepatic water content was determined by measuring wet/ dry weight ratios. Liver protein concentration was determined by means of protein assay (Bio-Rad).

\section{Proliferation}

Liver cell proliferation was determined by means of immunohistochemical staining for proliferative cell nuclear antigen (PCNA). PCNA stains proliferating cells during the $\mathrm{G}_{1}-\mathrm{M}$ cycle. To determine proliferating cells, sections were deparaffinized, rehydrated, and treated with proteases and $\mathrm{HCl}$ to decrease background contamination. Nonspecific antigen-binding sites were bound by incubating sections with goat serum, after which the sections were incubated with PCNA-horseradish peroxidase conjugate (SC-56) at a 1:50 dilution overnight at $4^{\circ} \mathrm{C}$ and then washed with phosphatebuffered saline. Finally, the sections were treated with diaminobenzidine-hydrogen peroxidase for 3 to 6 minutes under microscopic control and counterstained with Mayer's hematoxylin.
PCNA-positive cells (stained red-brown) were counted on 2 sections from each animal. In each section 2 masked observers selected 4 different sections for counting PCNA-positive cells. Proliferating cells were identified as those with a brown staining of the nucleus or cytoplasm. All hepatocytes within the field were counted, and proliferation was expressed as a percentage of proliferating cells per 100 hepatocytes. Values for all sections were averaged to calculate proliferation for the livers of each animal.

\section{Apoptosis}

We used the terminal deoxyuridine nick end-labeling immunohistochemical method (ApopTag, Chemicon) for histologic identification of apoptotic cells in the liver. Formalin-fixed tissues were processed and embedded in paraffin. Sections of $4 \mu \mathrm{m}$ obtained at 40- to $50-\mu \mathrm{m}$ intervals were deparaffinized, rehydrated in graded alcohol, and washed in deionized water. Protein was digested with proteinase $\mathrm{K}(20 \mu \mathrm{L} / \mathrm{mL}$ in phosphate-buffered saline) to decrease background contamination. The sections were then incubated with freshly prepared terminal deoxyribonucleotidyl transferase enzyme at $37^{\circ} \mathrm{C}$ for 2 hours. After the enzyme incubation, the sliders were incubated with antidigoxigenin peroxidase at room temperature for 30 minutes. The sections were thoroughly washed, and diaminobenzidine-hydrogen peroxidase was applied for color development for 3 to 6 minutes under microscopic control. Lastly, the sections were counterstained with Mayer's hematoxylin and mounted.

Two sections of each block of tissue were obtained at 40- to $50-\mu \mathrm{m}$ intervals. In each section one masked observer selected 5 fields in 4 different sections (approximately 5500 cells) for counting terminal deoxyuridine nick end-labeling-positive cells. Apoptotic cells were identified as those with a brown staining of the nucleus or as apoptotic bodies, which are fragments of apoptotic cells engulfed by neighboring epithelial cells.

All hepatocytes within the field were counted, and apoptosis was expresses as a percentage of apoptotic cells per 1000 hepatocytes. Values for all sections were averaged to calculate apoptosis for the liver of each animal.

\section{Statistical Analysis}

All data are presented as means \pm standard deviation. Comparisons between groups were analyzed by means of 2-way repeatedmeasures analysis of variance and the unpaired Student $t$ test. Correlation between data was analyzed with linear regression. All statistical analyses were performed with SPSS 10.0 software (SPSS, Inc). 
Table 2. Changes in serum rat GH, human GHBP, human IGF-I, and human IGFBP-3 levels

\begin{tabular}{lcccc}
\hline Variables & Groups & Pre-CPB & Off CPB & After $\mathbf{3 ~ h}$ \\
\hline Rat GH $(\mu \mathrm{g} / \mathrm{mL})$ & Group C & $13.6 \pm 0.7$ & $7.9 \pm 0.9$ & $5.8 \pm 0.7$ \\
& Group G & $14.8 \pm 1.2$ & $11.9 \pm 1.1^{*}$ & $7.1 \pm 0.8^{*}$ \\
hGHBP $(\mu \mathrm{g} / \mathrm{mL})$ & Group C & $11.3 \pm 1.1$ & $1.5 \pm 0.8$ & $5.1 \pm 0.4$ \\
& Group G & $13.4 \pm 0.9$ & $10.1 \pm 0.7^{*}$ & $7.9 \pm 0.6^{*}$ \\
hIGF-I $(\mu \mathrm{g} / \mathrm{mL})$ & Group C & $10.1 \pm 0.7$ & $1.9 \pm 0.5$ & $4.5 \pm 0.6$ \\
hIGFBP-3 $(\mu \mathrm{g} / \mathrm{mL})$ & Group G & $11.3 \pm 1.1$ & $1.3 \pm 0.7^{*}$ & $1.1 \pm 0.5$ \\
& Group C & $2.1 \pm 0.7$ & $3.5 \pm 1.1^{*}$ & $3.9 \pm 1.4^{*}$
\end{tabular}

Data are expressed as means \pm standard deviation. $C P B$, Cardiopulmonary bypass; pre- $C P B$, before the initiation of $C P B$; off $C P B$, at the termination of CPB; after $3 h, 3$ hours after CPB termination; $G H$, growth hormone; group $C$, control group; group $G$, growth hormone administration group; $h G H B P$, human growth hormone-binding protein; $h / G F-I$, human insulin-like growth factor I; $h / G F B P-3$, human insulin-like growth factor-binding protein 3 . ${ }^{*} P<.05$ versus group C.

\section{Results}

As for mean body weight, body temperature, hemoglobin value, and $\mathrm{PO}_{2}$, there were no significant differences among the groups before CPB. There were no technical failures or operative deaths in the animals used in this study. There were no significant differences in hemoglobin level at any sampling point between the groups, and the degree of CPBinduced hemodilution was considered similar in the 2 groups.

Serum GH, GHBP, IGF-I, and IGFBP-3 levels

Serum human GHBP levels were increased at CPB termination and 3 hours after CPB termination compared with those in group $\mathrm{C}(P<.05)$. Endogenous rat $\mathrm{GH}$ levels in group $\mathrm{C}$ were higher than in those in group $\mathrm{G}(P<.05)$.
Administration of rhGH also increased serum levels of both IGF-I and IGFBP-3 at CPB termination and 3 hours after $\mathrm{CPB}$ termination compared with those seen in group $\mathrm{C}(P<$ .05 , Table 2).

\section{Liver Function}

There was significant liver injury at CPB termination and 3 hours after $\mathrm{CPB}$ termination in both groups. Administration of rhGH decreased serum levels of alanine aminotransferase at $\mathrm{CPB}$ termination and 3 hours after $\mathrm{CPB}$ termination compared with those seen in group $\mathrm{C}(P<.05)$. rhGH also decreased serum levels of total bilirubin at 3 hours after CPB termination compared with levels in group $\mathrm{C}(P<.01$, Table 3). No difference between groups could be shown for serum albumin levels.

Table 3. Changes in liver function and serum constitutive hepatic protein, APP, and cytokine levels

\begin{tabular}{|c|c|c|c|c|}
\hline Variables & Groups & Pre-CPB & Off CPB & After $3 \mathrm{~h}$ \\
\hline \multirow[t]{2}{*}{ ALT (IU/L) } & Group C & $32.6 \pm 3.6$ & $130.9 \pm 7.5$ & $193.5 \pm 11.5$ \\
\hline & Group G & $33.5 \pm 2.9$ & $92.1 \pm 6.4^{*}$ & $123.1 \pm 9.2 \dagger$ \\
\hline \multirow[t]{2}{*}{ TB $(\mu \mathrm{mol} / \mathrm{L})$} & Group C & $14.8 \pm 3.5$ & $29.3 \pm 3.7$ & $45.3 \pm 4.8$ \\
\hline & Group G & $14.1 \pm 3.1$ & $20.3 \pm 5.1^{*}$ & $34.5 \pm 4.9 \dagger$ \\
\hline \multirow[t]{2}{*}{ Prealbumin (mg/L) } & Group C & $288.6 \pm 6.3$ & $215.6 \pm 47.6$ & $176.6 \pm 45.6$ \\
\hline & Group G & $291.3 \pm 5.6$ & $242.6 \pm 45.4^{*}$ & $228.6 \pm 46.8^{*}$ \\
\hline \multirow[t]{2}{*}{ Transferrin (mg/dL) } & Group C & $71.6 \pm 5.7$ & $55.3 \pm 3.9$ & $42.1 \pm 2.5$ \\
\hline & Group G & $70.2 \pm 4.9$ & $64.8 \pm 6.1^{*}$ & $49.8 \pm 3.9^{*}$ \\
\hline \multirow{2}{*}{ CRP (mg/dL) } & Group C & $4.6 \pm 0.8$ & $12.3 \pm 1.7$ & $18.9 \pm 2.0$ \\
\hline & Group G & $4.8 \pm 0.6$ & $9.8 \pm 2.6^{*}$ & $14.1 \pm 1.2^{*}$ \\
\hline \multirow[t]{2}{*}{ SAA (pg/dL) } & Group C & $321.3 \pm 6.7$ & $502.3 \pm 7.9$ & $618.7 \pm 11.6$ \\
\hline & Group G & $318.6 \pm 6.1$ & $445.8 \pm 8.4^{*}$ & $525.1 \pm 12.5^{*}$ \\
\hline \multirow[t]{2}{*}{ TNF- $\alpha(\mathrm{pg} / \mathrm{dL})$} & Group C & $11.2 \pm 0.7$ & $60.3 \pm 4.9$ & $145.1 \pm 8.5$ \\
\hline & Group G & $10.9 \pm 0.4$ & $44.5 \pm 3.8^{*}$ & $114.3 \pm 5.3^{*}$ \\
\hline \multirow[t]{2}{*}{ IL-1 $\beta$ (pg/dL) } & Group C & $18.6 \pm 1.7$ & $77.3 \pm 4.2$ & $158.2 \pm 9.3$ \\
\hline & Group G & $17.1 \pm 1.4$ & $59.2 \pm 3.9^{*}$ & $106.5 \pm 10.5^{*}$ \\
\hline
\end{tabular}

Data are expressed as means \pm standard deviation. $C P B$, Cardiopulmonary bypass; pre-CPB, before the initiation of CPB; off $C P B$, at the termination of $\mathrm{CPB}$; after $3 h, 3$ hours after CPB termination; $A L T$, alanine aminotransferase; group $C$, control group; group $G$, growth hormone administration group; $T B$, total bilirubin; $C R P, C$-reactive protein; $S A A$, serum amyloid A; TNF- $\alpha$, tumor necrosis factor $\alpha$; IL- $1 \beta$, interleukin $1 \beta$. ${ }^{*} P<.05$ versus group $C,+P<$ .05 versus group $\mathrm{C}$. 


\section{Serum Constitutive Hepatic Proteins}

All serum constitutive hepatic proteins decreased time dependently to less than normal levels after CPB. rhGH significantly increased prealbumin and transferrin levels at $\mathrm{CPB}$ termination and 3 hours after $\mathrm{CPB}$ termination compared with those in group $\mathrm{C}(P<.05$, Table 3$)$.

\section{Serum APPs}

All APP levels determined in this study increased time dependently above normal levels after CPB. Administration of rhGH decreased serum levels of type I APP SAA and $\mathrm{CRP}$ significantly at $\mathrm{CPB}$ termination and 3 hours after $\mathrm{CPB}$ termination compared with those in group $\mathrm{C}(P<.05$, Table $3)$. No difference between groups could be found in serum levels of type II APPs.

\section{Serum Cytokines}

All cytokine levels increased time dependently after CPB. Administration of rhGH decreased serum levels of TNF- $\alpha$ and IL- $1 \beta$ significantly at CPB termination and 3 hours after CPB termination compared with those in group $\mathrm{C}(P<.05$, Table 3$)$. No difference between groups could be found in serum levels of IL-6 and IL-10.

\section{Liver Changes}

In both groups liver weight increased at 3 hours after CPB termination compared with before the initiation of CPB. This increase in liver weight was associated with an increase in hepatic water content: the wet/dry weight ratio was increased in both groups at 3 hours after CPB termination compared with before the initiation of $\mathrm{CPB}$. rhGH treatment significantly decreased the hepatic water assimilation at 3 hours after $\mathrm{CPB}$ termination compared with that seen in group C (group G vs group C: $0.66 \pm 0.01$ vs $0.71 \pm 0.01$; $P<.05)$. rhGH significantly increased hepatic protein concentration at 3 hours after CPB termination compared with that seen in group $\mathrm{C}$ (group $\mathrm{G}$ vs group $\mathrm{C}: 0.98 \pm 0.05$ vs $0.89 \pm 0.02 \mathrm{mg} / \mathrm{mL} ; P<.05)$.

\section{Proliferation}

Hepatocyte proliferation increased in both groups at 3 hours after CPB termination when compared with physiologic hepatocyte proliferation. Administration of rhGH increased mitogenic activity of hepatocytes at 3 hours after $\mathrm{CPB}$ termination compared with that seen in group $\mathrm{C}(P<.05$, Figure 1).

\footnotetext{
Apoptosis

Hepatocyte apoptosis increased time dependently after CPB in both groups. rhGH decreased hepatocyte apoptosis at 3 hours after $\mathrm{CPB}$ termination compared with that seen in group $\mathrm{C}(P<.05$, Figure 2$)$.
}

\section{Discussion}

CPB-induced acute liver injury is a life-threatening complication after cardiac surgery and is thought to be associated with inflammatory responses and APRs. The present study uses a rat model to ascertain whether $\mathrm{GH}$ attenuates $\mathrm{CPB}$ induced hepatic APRs aroused by proinflammatory cytokines and thereby protects the liver.

The liver plays a critical role in the APR. The hepatic APR is initiated by the organism in response to injury, with the aim of restoring homeostasis. ${ }^{16,17}$ However, because a prolonged and uncontrolled increase of this response might be detrimental, a decrease would improve survival and clinical outcomes. ${ }^{18,19}$ Mediators of the APR are cytokines, including the IL- 1 family (IL- $1 \alpha / \beta$ and TNF- $\alpha / \beta$ ) and the IL-6 family (eg, IL-6 and IL-11). ${ }^{17}$ Synthesis and expression of these cytokines subsequently regulate the synthesis of APPs. ${ }^{17}$ The IL-1 family regulates synthesis of type I APPs, such as SAA, CRP, and $\alpha_{1}$-acid glycoprotein. The IL-6 family regulates synthesis of type II APPs, such as heptoglobin, fibrinogen, and $\alpha_{1}$-antitrypsin. In our experiment, although CPB-induced responses increased proinflammatory responses, as indicated by increases in both TNF- $\alpha$ and IL- $1 \beta$ levels, these were lower in rats in group G. Decreases in serum TNF- $\alpha$ and IL- $1 \beta$ levels were associated with decreased type I APP SAA, CRP, and $\alpha_{1}$-acid glycoprotein levels. These findings are in agreement with published data from a rat study ${ }^{15}$; GH could modulate the APR but had no effect on IL-6-like cytokines and type II APPs on burned rats. The results indicate the possibility of using rhGH to protect patients who undergo cardiovascular surgery with $\mathrm{CPB}$ from the detrimental systemic inflammatory response (Figure 3).

The mechanism by which GH modulates the APR are not entirely defined; however, it has been demonstrated that GH binds to its cell-surface receptor and lead to tyrosine phosphorylation of the CCAAT box/enhancer binding proteins $(\mathrm{C} / \mathrm{EBP}-\alpha)$, the activator protein-1 family of transcription factors, intracellular tyrosine kinases (Janus kinases [JAKs]), octamer-binding proteins, and signal transducers and activators of transcription (STATs). ${ }^{13,15,20}$ These signal transcription factors translocate to the nucleus, where they can interact with specific DNA sequences to modulate the gene expression of c-fos/c-jun and nuclear factor (NF) $\kappa \mathrm{B}$, which regulate the expression of the constitutive hepatic protein and APPs. ${ }^{15,20,21}$ Interestingly, IL-1-like cytokines regulate constitutive hepatic and APP expression through a similar cascade. ${ }^{17}$ The stimulation of these signals activates the transcription and translation of type I APP genes. Furthermore, many type I APPs contain NF- $\kappa$ B response elements in their promoter regions but not the type II APPs. ${ }^{17}$ NF- $\kappa$ B controls the transcriptional regulation of many proinflammatory cytokines, including IL-1 $\beta$ and TNF- $\alpha \cdot{ }^{17,20}$ Modulating NF- $\kappa$ B activation might cause a 

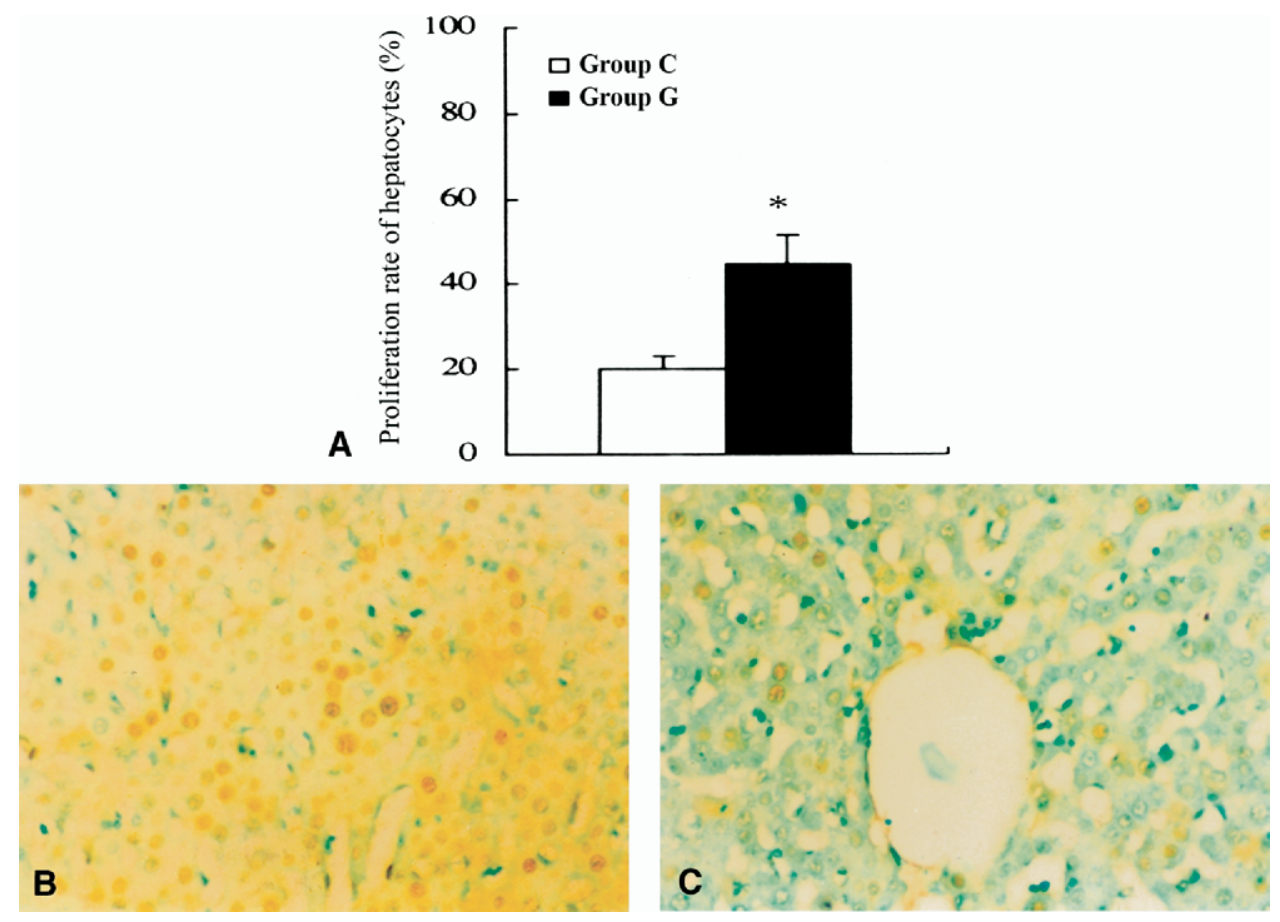

Figure 1. A, Rats in group $G$ showed higher mitogenic activity of hepatocytes 3 hours after CPB versus control animals $\left({ }^{*} P<.05\right)$. Data are presented as means \pm standard deviation. B, Proliferation rates of hepatocytes (proliferative cell nuclear antigen index) in a representative section in rats receiving recombinant human growth hormone 3 hours after cardiopulmonary bypass. Hepatocytes that stained dark brown were identified as hepatocytes that underwent mitosis and were considered to be positive. Magnification $\times 200$. C, Proliferation rates of hepatocytes (proliferative cell nuclear antigen index) in a representative section in rats receiving saline 3 hours after cardiopulmonary bypass. Compared with panel $B$, only a few hepatocytes were identified to undergo mitosis. Magnification $\times 200$. Group C, Control group; group $\mathbf{G}$, growth hormone administration group.

decrease in IL-1-like cytokines and type I APPs. Given that $\mathrm{GH}$ decreases IL-1-like cytokine levels, it is unknown whether GH decreases type I APP levels through a direct downregulation or through modulation of IL-1-like cytokine expression, which decreases these cellular signals and consecutively decreases type I APP levels. ${ }^{15,17,22}$

In contrast to APPs, constitutive hepatic protein levels are decreased during the APR because of a reprioritization of the liver during the APR; that is, the liver reprioritizes its synthesis from constitutive hepatic proteins toward APPs to restore systemic homeostasis. ${ }^{17}$ However, constitutive hepatic proteins fulfill important physiologic functions. ${ }^{23}$ Their downregulation has been described as potentially harmful, and syntheses of these proteins have been used as predictors for mortality, clinical markers for nutritional status and severity of stress, and indicators of improved recovery. ${ }^{12,23}$ In the present study we demonstrated that CPB decreased constitutive hepatic proteins. GH administration increased endogenous prealbumin, transferrin, and total protein concentrations. Similar to the APPs, the mechanism by which $\mathrm{GH}$ increases the concentrations of endogenous con- stitutive hepatic proteins is unknown; however, $\mathrm{GH}$ might exert this effect through activation of C/EBP- $\alpha{ }^{24} \mathrm{C} / \mathrm{EBP}-\alpha$ is a transactivator of liver-specific genes, such as albumin and transferrin, and its messenger RNA concentration decreases during trauma and stress and can be considered as a negative regulated acute-phase gene. ${ }^{17} \mathrm{C} / \mathrm{EBP}-\alpha$ messenger RNA levels, which are decreased after trauma, were shown to increase with $\mathrm{GH}$, indicating that a stimulation of the $\alpha$-isoform might lead consecutively to a stimulation of constitutive hepatic proteins, such as prealbumin and retinol-binding protein. ${ }^{25}$ We suggest that this increase in constitutive hepatic protein levels might be due to a decrease in production of APPs, which allows the liver, at least in part, to redirect its liver protein synthesis.

$\mathrm{GH}$ also can exert its effect through stimulation of IGF-I. IGF-I activates JAK/STAT transcription factors during the $\mathrm{APR}$, as well as $\mathrm{C} / \mathrm{EBP}-\alpha$ receptors, and $\mathrm{C} / \mathrm{EBP}-\alpha$ stimulates IGF-I expression. ${ }^{26}$ IGF-I might activate the same transcription factors as GH, indicating that the IGF-I, JAK/ STAT, and C/EBP- $\alpha$ cascade might be a major axis in modulating the APR that can be activated through $\mathrm{GH}$, 

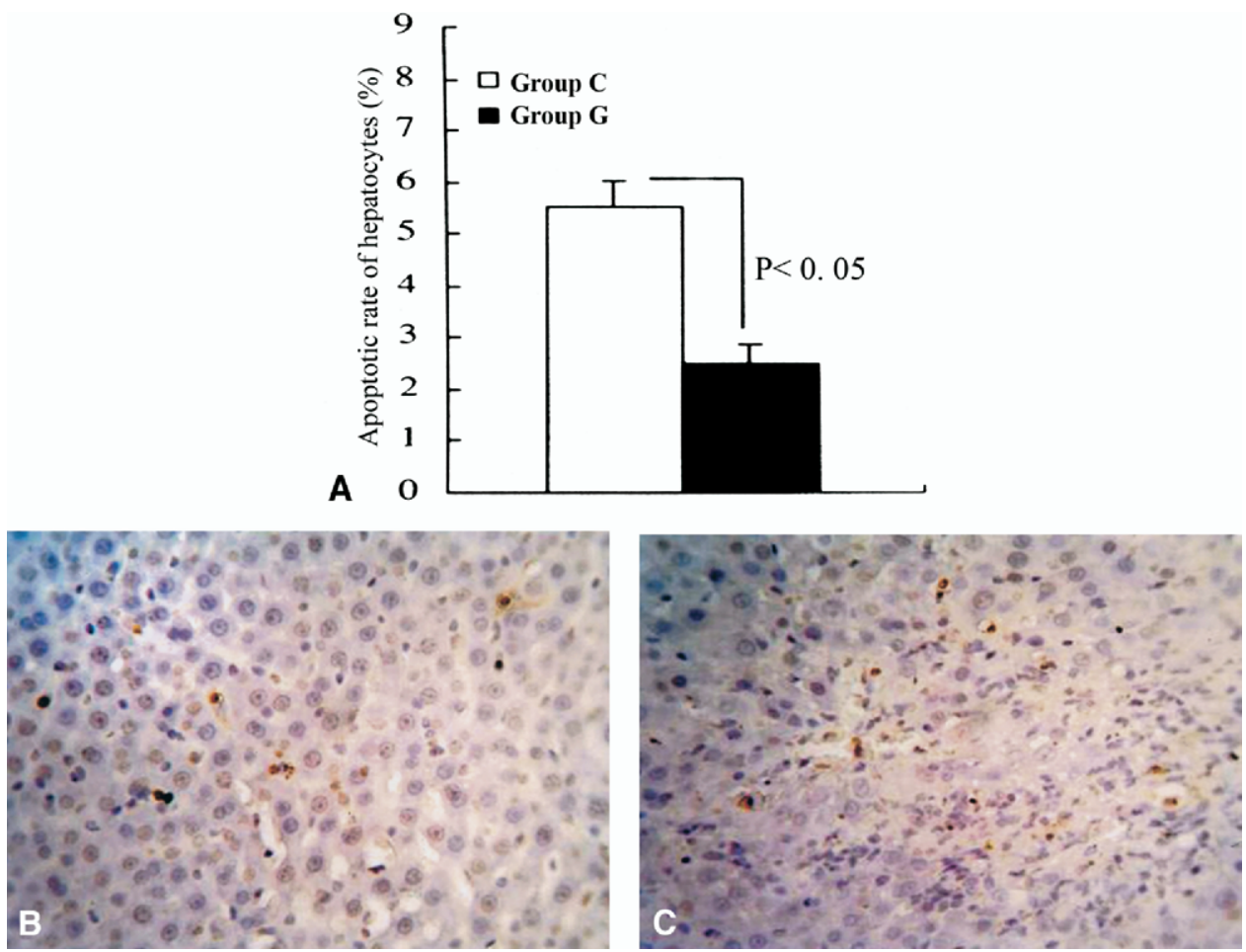

Figure 2. A, Rats in group C showed higher apoptotic activity of hepatocytes 3 hours after cardiopulmonary bypass versus rats in group G. Data are presented as means \pm standard deviation. B, Apoptotic rates of hepatocytes (terminal deoxyuridine nick end-labeling index) in a representative section in rats receiving recombinant human growth hormone 3 hours after cardiopulmonary bypass. Only a few hepatocytes were identified that underwent apoptosis (stained dark brown) and were considered to be positive. Magnification $\times 200$. C, Apoptotic rates of hepatocytes (terminal deoxyuridine nick end-labeling index) in a representative section in rats receiving saline 3 hours after cardiopulmonary bypass. Compared with panel B, more hepatocytes were identified to undergo apoptosis. Magnification $\times 200$. Group $C$, Control group; group $\mathbf{G}$, growth hormone administration group.

IGF-I, or both substances. ${ }^{27}$ We demonstrated in this study that serum IGF-I and IGFBP-3 levels were increased with exogenous $\mathrm{GH}$ administration, indicating that the GH/IGF-I axis might play an important role during the APR in CPB.

Preservation of organ homeostasis depends on a balance between cell proliferation and cell death. ${ }^{28} \mathrm{CPB}$ has been shown to induce epithelial cell apoptosis with a concomitant loss in cellular mass and absorptive surface of the small bowel and to induce apoptosis in myocardial cells with impairment in cardiac function. ${ }^{29}$ Alterations in the balance between apoptosis and proliferation might lead to changes in organ function, integrity, and homeostasis. ${ }^{28,29}$ Thus it might be beneficial after CPB for the organ function either to increase proliferation or decrease apoptosis. Our study demonstrated that $\mathrm{GH}$ increased hepatocyte proliferation and liver protein synthesis, indicating that $\mathrm{GH}$ might assuage the hypermetabolic response and diminish the negative nitrogen balance. Thus pretreatment with GH might be beneficial for liver function and systemic homeostasis for patients undergoing $\mathrm{CPB}$. We also showed that $\mathrm{CPB}$ induced hepatocyte apoptosis, which could be decreased by $\mathrm{GH}$ administration.

The mechanisms by which CPB induces hepatocyte apoptosis are not defined. Studies have suggested that in general hypoperfusion, ischemia and reperfusion, and increased levels of proinflammatory cytokine, such as IL$1 \alpha / \beta$, TNF- $\alpha$, and IL- 6 , are associated to promote apoptosis. ${ }^{29,30}$ In our experiment we did not examine the effect of $\mathrm{GH}$ on hepatic blood flow; however, we showed that $\mathrm{GH}$ decreased IL- $1 \beta$ and TNF- $\alpha$ levels. This attenuation might be the reason why $\mathrm{GH}$ decreases hepatocyte apoptosis.

In conclusion, $\mathrm{GH}$ prevents acute liver injury induced by CPB in rats through modulation of APR by affecting IGF-I and IL-1-like cytokine expression, which leads to decreased type I APP levels, IL-1-like cytokine synthesis, and hepatocyte apoptosis and increased constitutive hepatic proteins, total liver protein content, and hepatocyte proliferation. This 


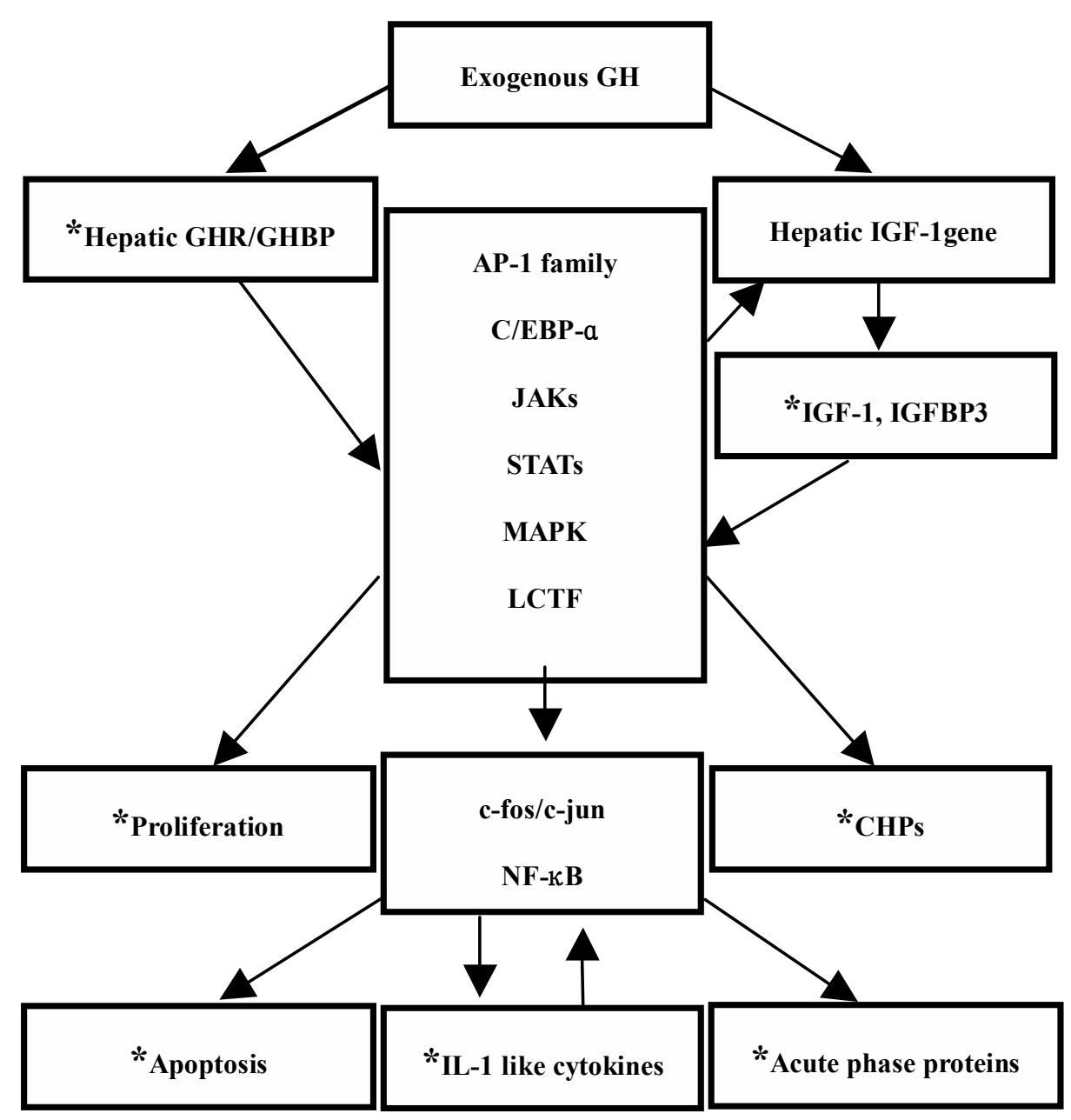

Figure 3. Potential targets and cascade effects of exogenous growth hormone. C/EBP, Tyrosine phosphorylation of the CCAAT box/enhancer-binding proteins; CHPs, constitutive hepatic proteins; GH, growth hormone; GHBP, growth hormone-binding protein; GHR, growth hormone receptor; IGF-I, human insulin-like growth factor I; hIGFBP-3, human insulin-like growth factor-binding protein 3; LCTF, latent cytoplasmic transcription factors; MAPK, mitogen-activated protein kinases; $N F-\kappa B$, nuclear factor $\kappa \mathrm{B} ; J A K s$, Janus kinases; STATs, signal transducers and activators of transcription. *Sites at which the growth hormone intervention acted in this experiment.

strategy of pretreatment with GH might be a prophylactic option to prevent liver injury when major cardiac surgery with CPB is performed. ${ }^{10,11,14}$

We thank Mrs Ping Zheng and Hong Chen for their technical support, the reviewers for critically reading the manuscript, and Andrew S. Wechsler, MD, for editorial assistance.

\section{References}

1. Franke A, Lante W, Fackeldey V, Becker HP, Kurig E, Zoller LG, et al. Pro-inflammatory cytokines after different kinds of cardio-thoracic surgical procedures: is what we see what we know? Eur J Cardiothorac Surg. 2005;28:569-75.

2. Michalopoulos A, Alivizatos P, Geroulanos S. Hepatic dysfunction following cardiac surgery: determinants and consequences. Hepatogastroenterology. 1997;5:779-83.
3. An Y, Xiao YB, Zhong QJ. Hyperbilirubinemia after extracorporeal circulation surgery: A recent and prospective study. World J Gastroenterol. 2006;12:6722-6.

4. Cagli K, Ulas MM, Ozisik K, Kale A, Bakuy V, Emir M, et al. The intraoperative effect of pentoxifylline on the inflammatory process and leukocytes in cardiac surgery patients undergoing cardiopulmonary bypass. Perfusion. 2005;20:45-51.

5. Morariu AM, Loef BG, Aarts LP, Rietman GW, Rakhorst G, van Oeveren W, et al. Dexamethasone: benefit and prejudice for patients undergoing on-pump coronary artery bypass grafting: a study on myocardial, pulmonary, renal, intestinal, and hepatic injury. Chest. 2005; $128: 2677-87$

6. Ueyama K, Nishimura K, Nishina T, Nakamura T, Ikeda T, Komeda M. PMEA coating of pump circuit and oxygenator may attenuate the early systemic inflammatory response in cardiopulmonary bypass surgery. ASAIO J. 2004;50:369-72.

7. van den Goor J, Nieuwland R, van den Brink A, van Oeveren W, Rutten P, Tijssen J, et al. Reduced complement activation during 
cardiopulmonary bypass does not affect the postoperative acute phase response. Eur J Cardiothorac Surg. 2004;26:926-31.

8. Varan B, Tokel K, Mercan S, Donmez A, Aslamaci S. Systemic inflammatory response related to cardiopulmonary bypass and its modification by methyl prednisolone: high dose versus low dose. Pediatr Cardiol. 2002;23:437-41.

9. Brix-Christensen V, Tonnesen E, Sorensen IJ, Bilfinger TV, Sanchez RG, Stefano GB. Effects of anaesthesia based on high versus low doses of opioids on the cytokine and acute-phase protein responses in patients undergoing cardiac surgery. Acta Anaesthesiol Scand. 1998; 42:63-70.

10. Wu X, Herndon DN, Wolf SE. Growth hormone down-regulation of Interleukin-1beta and Interleukin-6 induced acute phase protein gene expression is associated with increased gene expression of suppressor of cytokine signal-3. Shock. 2003;19:314-20.

11. Johnson TS, O'Leary M, Justice SK, Maamra M, Zarkesh-Esfahani $\mathrm{SH}$, Furlanetto R, et al. Differential expression of suppressors of cytokine signalling genes in response to nutrition and growth hormone in the septic rat. $J$ Endocrinol. 2001;169:409-15.

12. Chrysopoulo MT, Jeschke MG, Ramirez RJ, Barrow RE, Herndon DN. Growth hormone attenuates tumor necrosis factor alpha in burned children. Arch Surg. 1999;134:283-6.

13. Xu BC, Wang X, Darus CJ, Kopchick JJ. Growth hormone Promotes the association of transcription factor STAT5 with the growth hormone receptor. J Biol Chem. 1996;271:19768-73.

14. Jeschke MG, Barrow RE, Herndon DN. Recombinant human growth hormone treatment in pediatric burn patients and its role during the hepatic acute phase response. Crit Care Med. 2000;28:1578-84

15. Jeschke MG, Herndon DN, Wolf SE, DebRoy MA, Rai J, Lichtenbelt $\mathrm{BJ}$, et al. Recombinant human growth hormone alters acute phase reactant proteins, cytokine expression, and liver morphology in burned rats. J Surg Res. 1999;83:122-9.

16. Yumet G, Shumate ML, Bryant DP, Lang CH, Cooney RN. Hepatic growth hormone resistance during sepsis is associated with increased suppressors of cytokine signaling expression and impaired growth hormone signaling. Crit Care Med. 2006;34:1420-7.

17. Moshage H. Cytokines and the hepatic acute phase response. J Pathol. 1997; 181:257-66.
18. Livingston DH, Mosenthal AC, Deitch EA. Sepsis and multiple organ dysfunction syndromes: a clinical-mechanistic overview. New Horizons. 1995;3:257-66.

19. De Maio A, de Mooney ML, Matesic LE, Paidas CN, Reeves RH Genetic component in the inflammatory response induced by bacterial lipopolysaccharide. Shock. 1998;10:319-23.

20. Siebenlist U, Franzoso G, Brown K. Structure, regulation and function of NF-kappaB. Ann Rev Cell Biol. 1994;10:405-55.

21. Nolten LA, Steenbergh PH, Sussenbach JS. Hepatocyte nuclear factor 1 alpha activates promoter 1 of the human insulin-like growth factor 1 gene via two distinct binding sites. Mol Endocrinol. 1995;9:1488-99.

22. Balteskard L, Unneberg K, Mjaaland M, Jenssen TG, Revhaug A. Growth hormone and insulin-like growth factor 1 promote intestinal uptake and hepatic release of glutamine in sepsis. Ann Surg. 1998; 228:131-8

23. Selzman CH, Shames BD, Miller SA, Pulido EJ, Meng X, Mcintyre $\mathrm{RC}$, et al. Therapeutic implications of interleukin-10 in surgical disease. Shock. 1998;10:3089-94.

24. Gilpin DA, Hsieh CC, Kuninger DT, Herndon DN, Papaconstantinou J. Effect of the thermal injury on the expression of transcription factors that regulate acute phase response genes: The response of C/EBP- $\alpha$, C/EBP- $\beta$, and C/EBP- $\delta$ to thermal injury. Surgery. 1996;119:674-82.

25. Jarrar D, Herndon DN, Wolf SE, Papaconstantinou J. Growth hormone treatment after burn affects expression of C/EBPs, regulators of the acute phase response [abstract]. J Burn Care Rehab. 1998;19 (suppl): S163.

26. Nolten LA, Steenbergh PH, Sussenbach JS. Hepatocyte nuclear factor 1 alpha activates promoter 1 of the human insulin-like growth factor 1 gene via two distinct binding sites. Mol Endocrinol. 1995;9:1488-99.

27. Lazarus DD, Moldawer LL, Lowry SF. Insulin-like growth factor 1 activity is inhibited by interleukin-1 alpha, tumor necrosis factoralpha, and interleukin-6. Lymphokine Cytokine Res. 1993;12:219-23.

28. Steller H. Mechanisms and genes of cellular suicide. Science. 1995; 267:1445-9.

29. Lightfoot E Jr, Horton JW, Maass DL, White DJ, McFarland RD, Lipsky PE. Major burn trauma in rats promotes cardiac and gastrointestinal apoptosis. Shock. 1999;11:29-34.

30. Bradham CA, Plumpe J, Manns MP, Brenner DA, Trautwein C. Mechanisms of hepatic toxicity. I. TNF-induced liver injury. Am J Physiol. 1998;275:G387-92. 